\title{
Label-free Binding Analysis of 4-(2-Pyridylazo)-resorcinol-based Composite Layer with Cobalt Ion Using Surface Plasmon Resonance Optical Sensor
}

\author{
Silvan Saleviter, ${ }^{1}$ Yap Wing Fen, ${ }^{1,2 *}$ Nur Alia Sheh Omar, ${ }^{1}$ \\ Wan Mohd Ebtisyam Mustaqim Mohd Daniyal, ${ }^{1}$ Jaafar Abdullah, ${ }^{3}$ \\ and Mohd Adzir Mahdi ${ }^{4}$ \\ ${ }^{1}$ Functional Devices Laboratory, Institute of Advanced Technology, Universiti Putra Malaysia, \\ 43400 UPM Serdang, Selangor, Malaysia \\ ${ }^{2}$ Department of Physics, Faculty of Science, Universiti Putra Malaysia, 43400 UPM Serdang, Selangor, Malaysia \\ ${ }^{3}$ Department of Chemistry, Faculty of Science, Universiti Putra Malaysia, 43400 UPM Serdang, Selangor, Malaysia \\ ${ }^{4}$ Wireless and Photonics Network Research Centre, Faculty of Engineering, Universiti Putra Malaysia, \\ 43400 UPM Serdang, Selangor, Malaysia
}

(Received March 26, 2020; accepted May 26, 2020)

Keywords: 4-(2-pyridylazo)-resorcinol, cobalt ion, surface plasmon resonance

Label-free measurements of small-molecule binding interactions are of high interest to researchers across multiple scientific disciplines. Label-free optical sensors based on surface plasmon resonance (SPR) have been widely used for detecting various targets including toxic heavy metals in solutions. In this research, an SPR optical sensor enhanced with a 4-(2-pyridylazo)-resorcinol (PAR)-based composite layer was employed for the detection of the cobalt ion $\left(\mathrm{Co}^{2+}\right)$. A binding analysis study was conducted by monitoring the interaction between $\mathrm{Co}^{2+}$ and the sensing layer thin film. In our experiment, there were no changes in SPR angle for a gold layer in contact with $\mathrm{Co}^{2+}$ of different concentrations, whereas the enhanced SPR sensor produced a maximum SPR angle shift of $0.328^{\circ}$. From the relationship between the angle shift and the concentration of $\mathrm{Co}^{2+}$, the sensor had a sensitivity of $0.2375^{\circ} \mathrm{ppm}^{-1}$ for concentrations of less than $1 \mathrm{ppm}, 0.0044^{\circ} \mathrm{ppm}^{-1}$ for concentrations of 1 to $10 \mathrm{ppm}$, and $0.00069^{\circ}$ $\mathrm{ppm}^{-1}$ for concentrations from 10 to $100 \mathrm{ppm}$. Further analysis was also carried out by calculating the full width at half maximum (FWHM), detection accuracy (DA), and signal-tonoise ratio (SNR). In the binding analysis, the experimental results were fitted with Langmuir, Freundlich, and Sips isotherm equations. It was found that the Sips isotherm equation most closely fitted the experimental data with an $R^{2}$ value of 0.96716 and a binding affinity of $1.649 \mathrm{ppm}^{-1}$.

\section{Introduction}

In recent years, the scientific community has been focusing on monitoring and improving public health and welfare through the advancement of sensor technology for the detection of

*Corresponding author: e-mail: yapwingfen@gmail.com https://doi.org/10.18494/SAM.2020.2858 
materials hazardous to the human body, such as viruses, bacterial agents, gases, toxic heavy metals, and other toxic materials. Several sensing methods, which can be categorized into label and label-free methods, have been developed. ${ }^{(1)}$ When applying a label-free sensor, the targeted molecules do not undergo any physical modification due to a reactive label, such as a fluorescence or radioactive dye used in the label method. ${ }^{(2)}$ Over the past few decades, a variety of label-free optical sensors have become well established, including surface plasmon resonance (SPR). ${ }^{(3,4)}$ This can be used in a versatile label-free optical sensor for detecting molecular interactions. ${ }^{(5-7)}$ The basic principle of an SPR sensor is that changes in resonance angle are observed, where the binding of a targeted molecule (analyte) on a sensor layer adjacent to the metal layer causes a change in refractive index near the metal surface. This changes the resonance angle, which is the angle with minimum reflectance. ${ }^{\left({ }^{8-13}\right)}$ Over the past decade, SPR has been receiving continuous attention from the scientific community owing to its advantages and for its use in the analysis of binding properties. ${ }^{(14-16)}$ As well as label-free measurement, SPR sensors also have the advantages of a simple preparation process, cost efficiency, high sensitivity, and fast and real-time analysis. ${ }^{(17,18)}$ However, one major drawback of these sensors is that the metal layer alone is insufficient as a sensing layer for binding analysis. ${ }^{(19-25)}$ To overcome this hindrance, active layers have been developed as the sensing element to improve the performance of SPR optical sensors. ${ }^{(26-30)}$ SPR optical sensors have been developed by introducing novel materials as the sensing layer to sense various analytes including heavy metals in the biomedical and environment fields. ${ }^{(31-34)}$ In this study, the potential of a 4-(2-pyridylazo)-resorcinol (PAR)-based material as an active layer for SPR sensors to enhance the detection of $\mathrm{Co}^{2+}$ is newly reported.

PAR is a well-known chromogenic reagent, a type of reagent that produces or changes color in a reaction. ${ }^{(35,36)}$ This compound is a popular reagent applied in spectrophotometric, chelatometric, and colorimetric analyses owing to its ability to correlate with many different metals. ${ }^{(37-42)}$ The versatility of this compound may be due to its several reactive sites, such as a pyridyl nitrogen atom, an azo group, and an o-hydroxyl group. ${ }^{(43)}$ The pyridyl group is derived from pyridine $\left(\mathrm{C}_{5} \mathrm{H}_{5} \mathrm{~N}\right)$ by removing a hydrogen atom from a ring carbon atom. The removal of the hydrogen atom provides room for bonding with an azo group $(-\mathrm{N}=\mathrm{N}-)$ at the second carbon. Resorcinol $\left(\mathrm{C}_{6} \mathrm{H}_{6} \mathrm{O}_{2}\right)$, on the other hand, is an organic compound synthesized from the destructive distillation of a natural resin. In its compound form, it appears as a white crystalline compound with a weak odor and a bittersweet taste. ${ }^{(44)}$ The reaction of resorcinol with 2-pyridylazo led to the synthesis of PAR for the first time in $1959 .{ }^{(45)}$ Since then, PAR has been widely used as a chromogenic reagent for the detection of mainly metal ions. ${ }^{(46,47)}$ Owing to its remarkable sensitivity towards a wide selection of metal ions, PAR has been integrated with other materials to improve the performance of sensors. ${ }^{(48,49)}$

Chitosan is a semicrystalline polymer material that is derived from chitin by deacetylation under alkaline condition. Chitosan is said to be the most important chitin derivative and much easier to process, and it has a good mechanical and optical properties. It is used to produce films, hydrogels, and fibers, and it is mostly used in the biomedical field because it is nontoxic, biodegradable, and biocompatible, and has excellent film-forming ability. ${ }^{(50)}$ In addition, chitosan has favorable metal ion adsorption properties owing to the existence of amine $\left(-\mathrm{NH}_{2}\right)$ and hydroxy $(-\mathrm{OH})$ groups in its chemical structure. These functional groups can serve as 
reaction sites for metal ions. ${ }^{(51)}$ Other than that, chitosan can be reinforced by blending it with other novel materials such as graphene-based materials. Graphene oxide (GO) is a watersoluble and insulating material that contains several oxygen-containing groups decorated on the basal planes and edges of GO, which include epoxy, hydroxyl, and carboxyl groups. ${ }^{(52)}$ These functional groups provide GO with functionalities, such as hydrophilicity, high surface activity, and antifouling properties. GO was also reported as a "precise and ultrafast" transport medium for ions and molecules in aqueous solutions, which makes GO a suitable candidate to be used as part of the sensing layer for metal ion detection using SPR. ${ }^{(53)}$

Cobalt (Co), which is an element with an atomic number of 27 , is located in the first transition series of Group 9 in the periodic table. In its metallic state, Co is a hard and silvery grey solid at room temperature with a relative molecular mass of 58.93. Co in compound forms mainly occurs as $\mathrm{Co}^{2+}$, which is commercially and environmentally obtainable. ${ }^{(54)}$ In addition, it is the 33rd most abundant element that can be found in almost all media, including water, air, soil, and sediment. $\mathrm{Co}^{2+}$ is one of the most important transition metals, which has been widely used in industries. For example, $\mathrm{Co}^{2+}$ was used in lithium ion battery electrode manufacturing and as a drying agent for paint industries. In the human biological system, $\mathrm{Co}^{2+}$ is very important owing to its role in vitamin $\mathrm{B}_{12}$. Studies also show that $\mathrm{Co}^{2+}$ deficiency can lead to cardiovascular diseases. However, as $\mathrm{Co}^{2+}$ is non-biodegradable, water pollution caused by this metal ion can be very hazardous to humans. For instance, excess intake of $\mathrm{Co}^{2+}$ can lead to permanent disability, decreased pulmonary function, thyroid damage, nodular fibrosis, vomiting, high blood pressure, and slowed respiration. ${ }^{(55,56)}$ Therefore, $\mathrm{Co}^{2+}$ detection is very crucial for health and allows the continuous monitoring of environmental water. Hence, in this study, the performance and binding of an SPR optical sensor enhanced with a PAR-based composite layer are explored towards contributing more information for the development of SPR as a powerful optical sensor for $\mathrm{Co}^{2+}$ detection.

\section{Materials and Methods}

\subsection{Materials and reagents}

Medium-molecular-weight (MMW) chitosan with an MW of 190000-310000 and a degree of deacetylation of $75-85 \%$, acetic acid (assay $\geq 99.7 \%$ ), and PAR were purchased from Sigma Aldrich (St. Louis, MO, USA). The GO $(4 \mathrm{mg} / \mathrm{mL})$ was purchased from Graphenea (Cambridge, MA, USA). The atomic adsorption spectroscopy standard solution (1000 ppm) of Co(II) was purchased from Merck (Darmstadt, Germany).

\subsection{Preparation of chemicals}

All chemicals used were of analytical grade, and deionized water was used for the preparation of all solutions. A stock PAR solution of $1.5 \times 10^{-3} \mathrm{~g} / \mathrm{ml}$ was prepared by mixing $0.15 \mathrm{~g}$ of PAR powder into $100 \mathrm{ml}$ of deionized water. A chitosan solution was prepared by dissolving $0.4 \mathrm{~g}$ of MMW chitosan in $50 \mathrm{ml}$ of $1 \%$ acetic acid. A cobalt standard solution with a concentration of $1000 \mathrm{ppm}$ was diluted with deionized water in accordance with the dilution 
formula $M_{1} V_{1}=M_{2} V_{2}$ to produce $\mathrm{Co}^{2+}$ solutions with concentrations of $0.01,0.1,1,5,10,20,40$, 60,80 , and $100 \mathrm{ppm}$.

\subsection{Preparation of composite thin film}

The preparation of the composite solution was started by mixing $50 \mathrm{ml}$ of the prepared chitosan solution with $10 \mathrm{ml}$ of GO solution. Then, PAR was immobilized inside the chitosanGO solution by mixing $5 \mathrm{ml}$ of $1.5 \times 10^{-3} \mathrm{~g} / \mathrm{ml}$ PAR with the chitosan-GO solution. The mixture was then stirred constantly and thoroughly for $24 \mathrm{~h}$ at room temperature.

Glass cover slips $\left(24 \times 24 \times 0.1 \mathrm{~mm}^{3}\right.$, Menzel-Glaser, Germany) were cleaned using acetone to remove dirt from their surface before coating. A thin gold layer was first deposited on the slides using an SC7640 sputter coater. Then, spin coating (Specialty Coating System, P-6708D) was used to produce a chitosan-GO-PAR composite thin film on top of the gold layer. Approximately $0.55 \mathrm{ml}$ of the chitosan-GO-PAR composite solution was placed on the gold layer, covering most of the surface. The glass cover slip was spun at $6000 \mathrm{rev} / \mathrm{min}$ for $30 \mathrm{~s}$ to produce the Au/chitosan-GO-PAR thin film.

\subsection{SPR optical sensor}

SPR measurements were carried out using a custom-built instrument with the setup shown in Fig. 1. As shown in the figure, the He-Ne laser $(\lambda=632.8 \mathrm{~nm})$ was p-polarized to give out only the transverse magnetic (TM) mode of the laser to propagate through a prism (refractive index $n=1.77861$ at $632.8 \mathrm{~nm}$ ). The glass cover slip was attached to one side of the prism using a refractive index matching liquid, and a hollow cell was attached to the gold or Au/chitosanGO-PAR film surface to contain the $\mathrm{Co}^{2+}$ solution. The prism and hollow cell were mounted on a rotating plate to control the angle of the incident light. The He-Ne laser beam, which was incident to the prism (refractive index of 1.77861), passed through the sample (composite thin film), and the reflected beam was detected using a large-area photodiode. The signal was then processed using a lock-in amplifier (SR 530). ${ }^{(57)}$

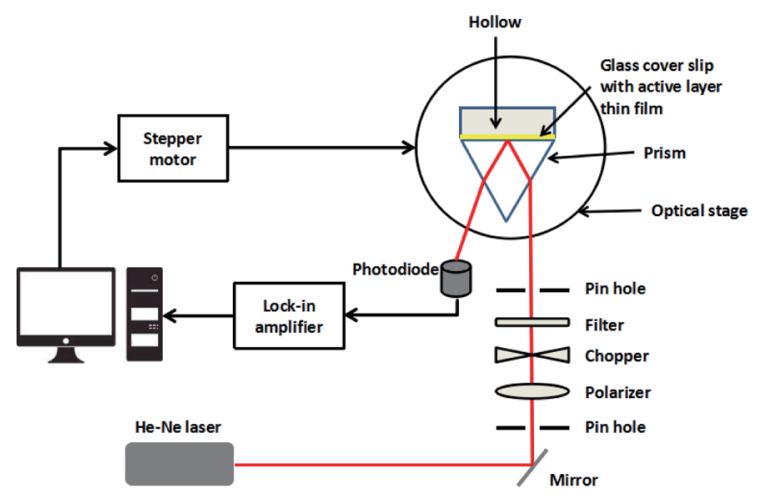

Fig. 1. (Color online) Schematic diagram of SPR spectroscopy experimental setup. 


\section{Results and Discussion}

\subsection{SPR optical sensor}

Initially, a preliminary SPR test was conducted with deionized water in contact with the gold (Au) layer. About $2 \mathrm{ml}$ of deionized water was injected into the cell in contact with the gold layer. The SPR reflectivity curve for the Au layer in contact with the deionized water is shown in Fig. 2. The resonance angle obtained was $54.49^{\circ}$.

The SPR experiment was then performed using aqueous solutions with different $\mathrm{Co}^{2+}$ concentrations, which were injected one after another into the cell attached to the gold layer so that ions could attach to the gold layer. The SPR reflectivity curves for $\mathrm{Co}^{2+}$ solutions with concentrations ranging from 20 to $100 \mathrm{ppm}$ in contact with the gold layer are shown in Fig. 3. From the SPR curves, the resonance angle was compared for all $\mathrm{Co}^{2+}$ concentrations. We can see that the resonance angle did not change with the $\mathrm{Co}^{2+}$ concentration, as also shown in Fig. 4. These results suggest that there were no changes in resonance angle for $\mathrm{Co}^{2+}$ of different

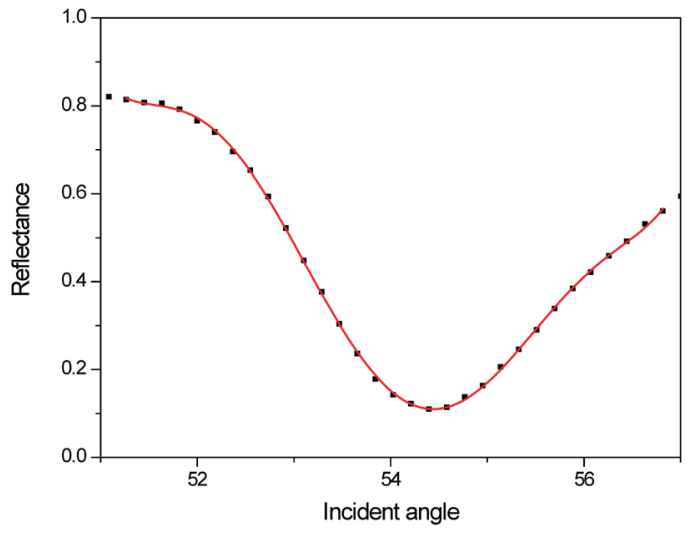

Fig. 2. (Color online) SPR curve of gold layer in contact with deionized water.

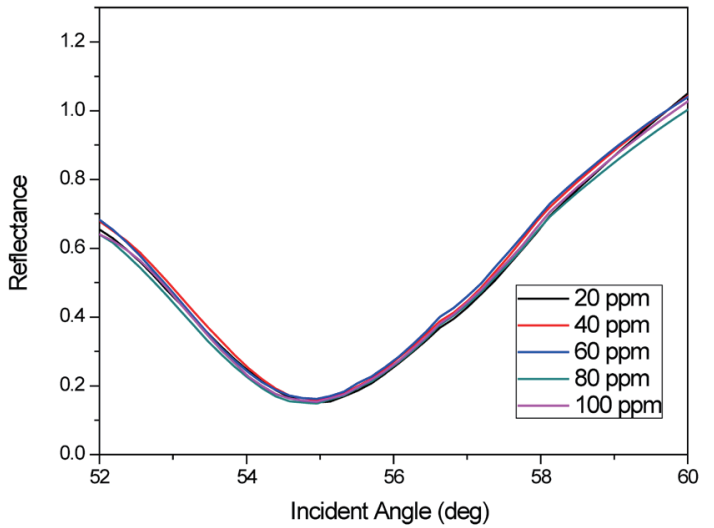

Fig. 3. (Color online) SPR curves for $\mathrm{Co}^{2+}$ $(20-100 \mathrm{ppm})$ in contact with the gold layer.

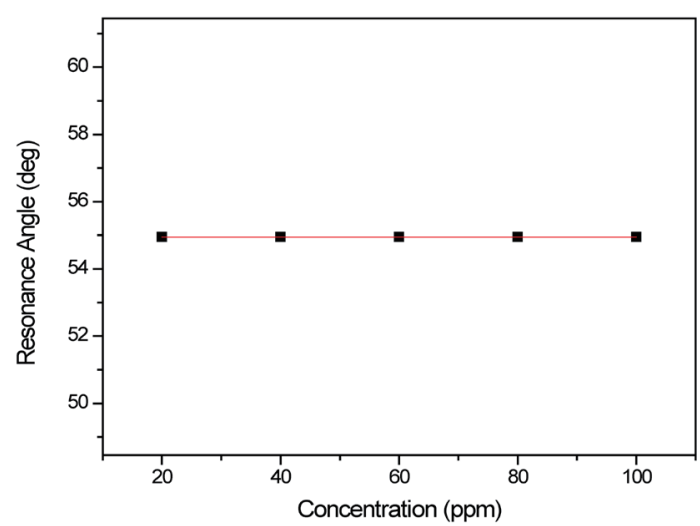

Fig. 4. (Color online) Resonance angle of gold layer in contact with $\mathrm{Co}^{2+}$ of different concentrations. 
concentrations in contact with the gold film. This result may be due to the small amount of $\mathrm{Co}^{2+}$ existing in the solution that was adsorbed on the gold surface. In addition, it can be due to the similarity of the refractive index for low concentrations of metal ions. ${ }^{(58)}$

\subsection{SPR optical studies of Au/chitosan-GO-PAR exposed to $\mathrm{Co}^{2+}$}

The SPR experiment on the detection of $\mathrm{Co}^{2+}$ in solution was continued by replacing the gold thin film with a Au/chitosan-GO-PAR thin film. The SPR experiment was first repeated with deionized water. The deposition of chitosan-GO-PAR on the gold thin film increased the resonance angle. The resonance angle for Au/chitosan-GO-PAR in contact with deionized water was $56.40^{\circ}$, compared with $54.49^{\circ}$ for only the gold film. This may be due to the increase in refractive index when the chitosan-GO-PAR thin film was deposited on top of the gold film. The SPR curve for Au/chitosan-GO-PAR in contact with deionized water is shown in Fig. 5 and was used to compare the results for different $\mathrm{Co}^{2+}$ concentrations to obtain the detection limit.

The SPR experiment was then carried out for solutions with $\mathrm{Co}^{2+}$ concentrations ranging from 0.01 to $100 \mathrm{pm}$, which were injected one after another into the cell. The SPR curves for the $\mathrm{Co}^{2+}$ solutions in contact with the immobilized PAR in the chitosan-GO thin film are shown in Fig. 6(a) for concentrations of 0.01 to $10 \mathrm{ppm}$ and in Fig. 6(b) for concentrations of 10 to $100 \mathrm{ppm}$. The resonance angles determined from the SPR curves are 56.458, 56.514, 56.652, $56.652,56.652,56.652,56.652,56.708,56.722,56.722$, and $56.792^{\circ}$ for deionized water and $\mathrm{Co}^{2+}$ concentrations of $0.01,0.1,1,5,10,20,40,60,80$, and $100 \mathrm{ppm}$, respectively. There is a slight increase in resonance angle with increasing $\mathrm{Co}^{2+}$ concentration.

Surprisingly, there was no shift in resonance angle between 0.1 and $20 \mathrm{ppm}$. This may due to the small number of $\mathrm{Co}^{2+}$ ions present and adsorbed on the thin film. However, there was a significant positive correlation between concentrations of 20 and $100 \mathrm{ppm}$ as the angle shifted. It is believed that the immobilization of PAR plays an important role in the detection of $\mathrm{Co}^{2+}$. It is difficult to explain this result, but it might be related to the $\mathrm{H}$ of the ortho-OH group of PAR

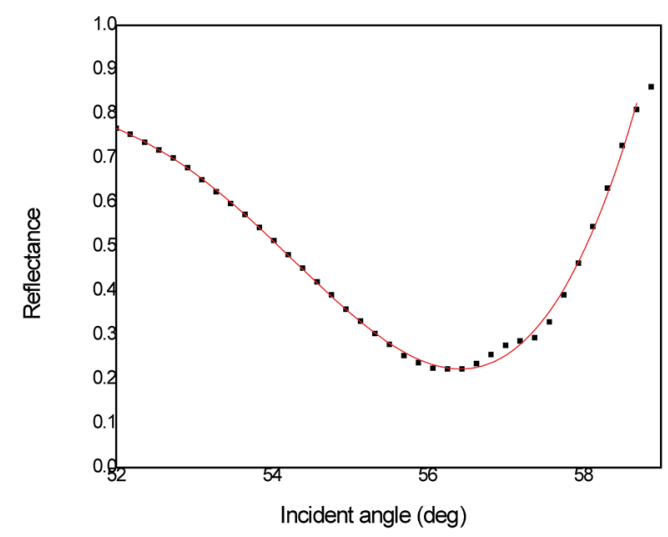

Fig. 5. (Color online) SPR curve for Au/chitosan-GO-PAR thin film in contact with deionized water. 


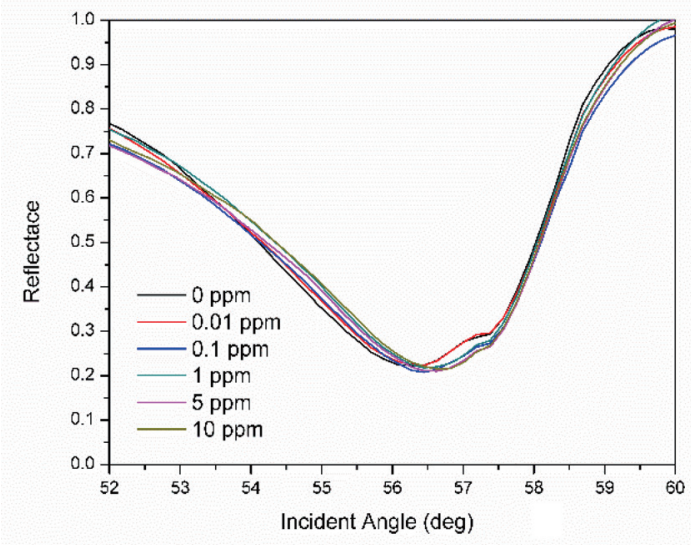

(a)

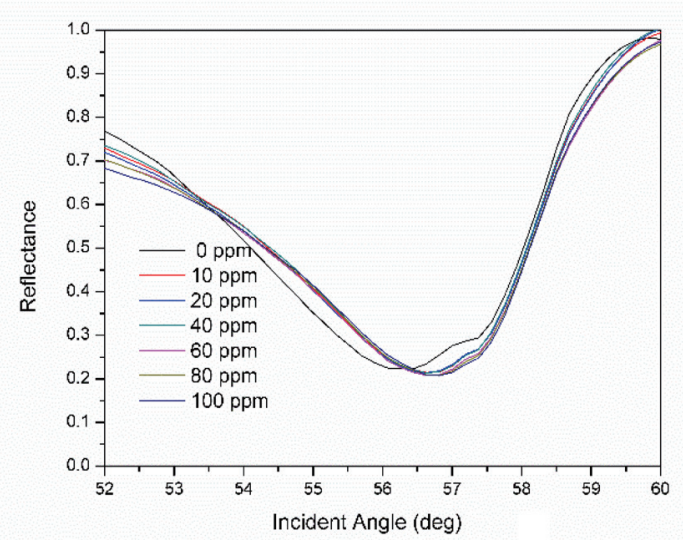

(b)

Fig. 6. (Color online) SPR reflectivity curves for Au/chitosan-GO-PAR thin film in contact with $\mathrm{Co}^{2+}$ of different concentrations: (a) 0.01 to $10 \mathrm{ppm}$; (b) 10 to $100 \mathrm{ppm}$.

being replaced by $\mathrm{Co}^{2+}$ after the rupture of hydrogen bonds with the formation of the metal to pyridine $\mathrm{N}$ and azo N. ${ }^{(49)}$

Furthermore, $\mathrm{Co}^{2+}$ may interact with the Au/chitosan-GO-PAR thin film, leading to the formation of a pair of shared electrons between the positive charge from $\mathrm{Co}^{2+}$ and the negative charge from the amine functional group in chitosan. In addition, graphene oxide increased the optical absorption in both the visible and infrared ranges. Thus, the sensitivity is enhanced in the presence of the chitosan-GO-PAR film as compared with the gold film only.

We believe that the Au/chitosan-GO-PAR thin film plays an important role in the detection of $\mathrm{Co}^{2+}$. The shift in resonance angle $(\Delta \theta)$ has been introduced as a parameter to measure the sensitivity of a sensor. ${ }^{(1)} \Delta \theta$ can be determined by taking the difference between the resonance angles for the sample and deionized water as a reference. The resonance angle and its shift for $\mathrm{Co}^{2+}$ of different concentrations in contact with the Au/chitosan-GO-PAR thin film are shown in Table 1.

There are no changes in resonance angle $(\Delta \theta=0)$ for $\mathrm{Co}^{2+}$ of different concentrations in contact with a bare gold film as shown in Fig. 4. However, when the chitosan-GO-PAR thin film was deposited on the gold layer, the resonance angle increased. The calculated resonance angle shift is plotted against the $\mathrm{Co}^{2+}$ concentration in the range of 0 to $100 \mathrm{ppm}$ in Fig. 7. Linear regression analyses were carried out to determine the sensitivity of this sensor, which can be obtained from the gradient of the linear regression line. The linear regression equation for concentrations of 0 to $1 \mathrm{ppm}$ is $\Delta \theta_{S P R}=0.2370\left(\mathrm{Co}^{2+}\right)$, which produces a slope of $0.2370^{\circ} \mathrm{ppm}^{-1}$ with $R^{2}$ of 0.6403 , and at higher concentrations of 10 to $100 \mathrm{ppm}$, the linear regression equation is $\Delta \theta_{S P R}=0.00069\left(\mathrm{Co}^{2+}\right)+0.2351$, where a slope of $0.00069^{\circ} \mathrm{ppm}^{-1}$ with $R^{2}$ of 0.9699 was obtained. Overall, the chitosan-GO-PAR active layer demonstrates high sensitivity towards $\mathrm{Co}^{2+}$ at lower concentrations, although the sensitivity is lower at high concentrations. Therefore, it can be concluded that this optical sensor for $\mathrm{Co}^{2+}$ based on a Au/chitosan-GO-PAR thin film is highly sensitive, with higher sensitivity at lower concentrations. 
Table 1

SPR resonance angle and shift in resonance angle for $\mathrm{Co}^{2+}$ solution with different concentrations in contact with $\mathrm{Au} /$ chitosan-GO-PAR thin film (0 ppm represents deionized water).

\begin{tabular}{ccc}
\hline Cobalt ion concentration $(\mathrm{ppm})$ & Resonance angle $\theta(\mathrm{deg})$ & Shift in resonance angle $\Delta \theta(\mathrm{deg})$ \\
\hline 0 & 56.427 & 0.000 \\
0.01 & 56.479 & 0.052 \\
0.1 & 56.586 & 0.159 \\
1 & 56.650 & 0.223 \\
5 & 56.659 & 0.232 \\
10 & 56.689 & 0.262 \\
20 & 56.696 & 0.269 \\
40 & 56.707 & 0.279 \\
60 & 56.721 & 0.294 \\
80 & 56.730 & 0.303 \\
100 & 56.755 & 0.328 \\
\hline
\end{tabular}

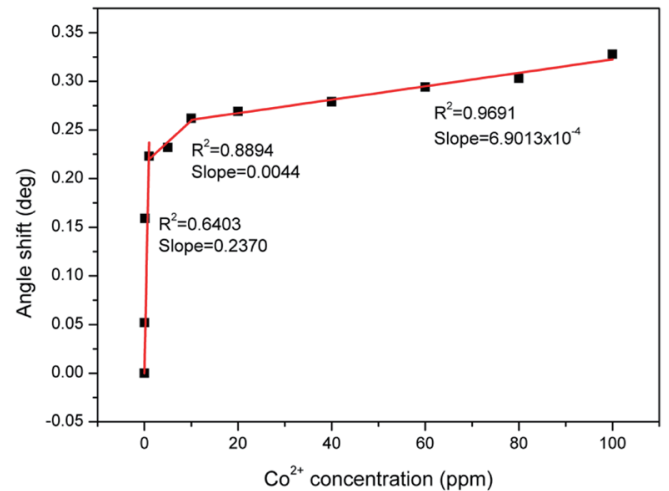

Fig. 7. (Color online) Shift of the resonance angle for $\mathrm{Co}^{2+}$ of different concentrations in contact with $\mathrm{Au} /$ chitosan-GO-PAR thin film.

\subsection{Performance parameter of the SPR optical signal}

By analyzing the SPR curve and data, some important parameters including the full width at half maximum (FWHM), detection accuracy (DA), and signal-to-noise ratio (SNR) were determined. The DA of the resonance angle depends on the width of the SPR curve: the narrower the SPR curve, the higher the DA. The DA is inversely proportional to the FWHM of the SPR reflectivity, where the FWHM can be defined as the angular width for the half value of the maximum SPR reflectivity curve. ${ }^{(59,60)}$ The FWHM can be determined by measuring the width of the reflectivity curve corresponding to the half value of the maximum reflectance as shown in Fig. 8. The obtained FWHM and DA of the Au/chitosan-GO-PAR SPR sensor upon the adsorption of $\mathrm{Co}^{2+}$ are shown in Table 2.

From Table 2, the FWHM decreases as the $\mathrm{Co}^{2+}$ concentration increases. The SPR curve of deionized water in contact with the active layer produced the largest FWHM of $4.29^{\circ}$, which decreased to $3.50^{\circ}$ as the concentration increased to $100 \mathrm{ppm}$. The DA increased rapidly until the concentration reached $10 \mathrm{ppm}$, then increased steadily from 10 to $100 \mathrm{ppm}$. In contrast to 


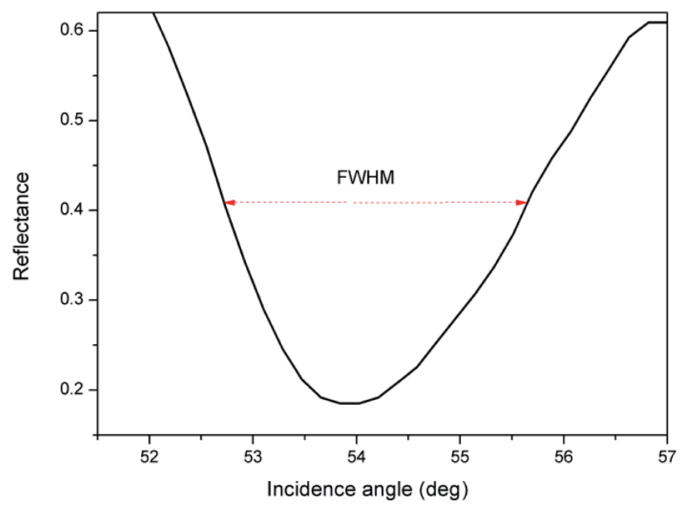

Fig. 8. (Color online) FWHM of SPR curve corresponding to half its maximum value.
Table 2

FWHM and DA values of Au/chitosan-GOPAR active layer in contact with $\mathrm{Co}^{2+}$ of different concentrations.

\begin{tabular}{ccc}
\hline $\mathrm{Co}^{2+}$ concentration $(\mathrm{ppm})$ & $\left.\mathrm{FWHM}^{\circ}\right)$ & $\mathrm{DA}\left(/^{\circ}\right)$ \\
\hline 0 & 4.2902 & 0.2331 \\
0.01 & 4.1398 & 0.2416 \\
0.1 & 3.9808 & 0.2512 \\
1 & 3.9375 & 0.2540 \\
5 & 3.7984 & 0.2633 \\
10 & 3.7935 & 0.2636 \\
20 & 3.7643 & 0.2657 \\
40 & 3.7347 & 0.2678 \\
60 & 3.7052 & 0.2700 \\
80 & 3.6289 & 0.2756 \\
100 & 3.4975 & 0.2859 \\
\hline
\end{tabular}

the FWHM, the DA increased with the concentration. This result supports the statement by Sharma et al. that a narrower FWHM gives a better DA. ${ }^{(61)}$ The SNR of the Au/chitosan-GOPAR SPR sensor in contact with $\mathrm{Co}^{2+}$ of different concentrations is shown in Fig. 10. The SNR also increases with the $\mathrm{Co}^{2+}$ concentration. Thus, we also conclude that the SNR also indicates the binding affinity owing to the concentration dependence of $\triangle \theta_{S P R}$. In addition, the SNR plots in Fig. 10 are similar to the shifts in SPR angle in Fig. 7. This shows that $\Delta \theta_{S P R}$ is more effective than the DA in determining the SNR. ${ }^{(12)}$

\subsection{Binding affinity via association equilibrium constant}

Equilibrium isotherm models were used to calculate the experimental sorption data. ${ }^{(62)}$ These equilibrium models may give some insight into the sorption mechanism and surface properties, and also the affinity of the sorbent. Langmuir and Freundlich isotherms are two of the most widely used analytical isotherms in adsorption studies to obtain the binding model of a metal ion with a sensor layer. ${ }^{(63)}$ The Freundlich isotherm was the earliest reported sorption isotherm equation, which was presented by Freundlich in 1906. ${ }^{(64)}$ This isotherm was derived by assuming an exponentially decaying sorption site energy distribution. The Freundlich equation used to describe a heterogeneous surface energy can be expressed as

$$
\Delta \theta_{\text {sat }}=K_{f} C^{n}
$$

where $K_{f}$ is the Freundlich constant, which is an affinity constant, $C$ is the $\mathrm{Co}^{2+}$ concentration, and $n$ is the heterogeneity index. ${ }^{(65)}$

The Langmuir model, on the other hand, is based on the assumption of greater adsorption energy for the first layer of adsorbed molecules in a homogeneous system without interaction between adsorbed molecules. ${ }^{(32)}$ According to the Langmuir theory, the saturated monolayer isotherm for metal ion adsorption on a sensor surface can be expressed as 


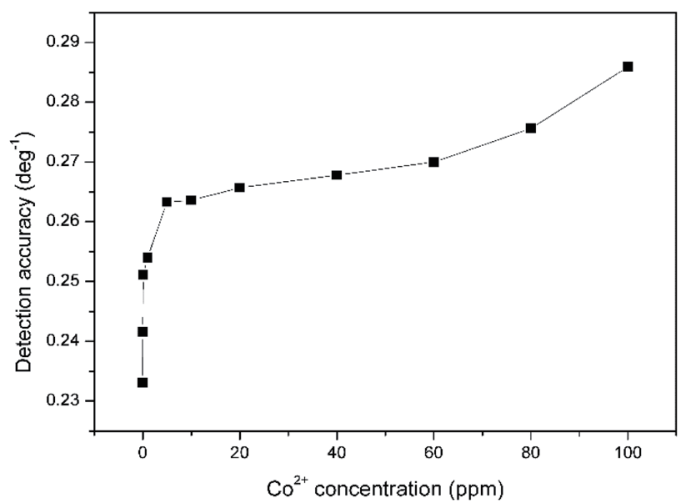

Fig. 9. DA of the chitosan-GO-PAR sensor for $\mathrm{Co}^{2+}$.

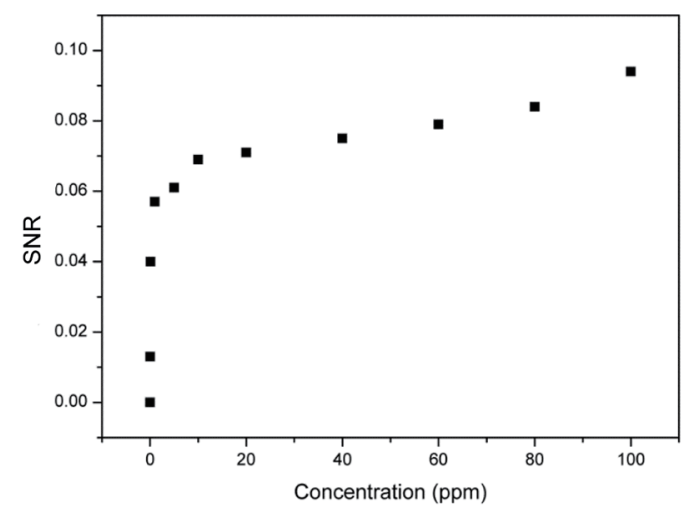

Fig. 10. SNR of the chitosan-GO-PAR sensor for $\mathrm{Co}^{2+}$.

$$
\Delta \theta_{\text {sat }}=\frac{\Delta \theta_{\max } K_{L} C}{1+K_{L} C}
$$

where $\Delta \theta_{\max }$ is the maximum resonance angle shift, $K_{L}$ is the Langmuir constant, which is an affinity constant, $C$ is the $\mathrm{Co}^{2+}$ concentration, and $n$ is the heterogeneity index. ${ }^{(16)}$

The Langmuir-Freundlich isotherm, also known as the Sips equation, is a versatile isotherm expression that can simulate both Langmuir and Freundlich behaviors. ${ }^{(66)}$ The Sips isotherm is a combination of both the Langmuir and Freundlich expressions that can be used to predict the behavior of a heterogeneous adsorption system and overcome the limitation of the Freundlich isotherm model at a higher adsorbate concentration. Generally, the equation parameters are affected mainly by the operating conditions, such as the concentration, $\mathrm{pH}$, and temperature. By combining both the Langmuir and Freundlich equations in Eqs. (1) and (2), the Sips equation can be expressed as

$$
\Delta \theta_{\text {sat }}=\frac{\Delta \theta_{\max }\left(K_{s} C\right)^{n}}{1+\left(K_{s} C\right)^{n}}
$$

where $K_{S}$ is the Sips or affinity constant, $C$ is the $\mathrm{Co}^{2+}$ concentration, and $n$ is the heterogeneity index. ${ }^{(60)}$ By using the Sips isotherm model, one can vary the density function for a heterogeneous system by varying the heterogeneity index $n$ from 0 to 1 . For a homogeneous material, $n$ is 1 , and for a heterogeneous material, $n$ is less than 1 .

In this study on the association of Au/chitosan-GO-PAR, the angle shift data plot was fitted with Freundlich, Langmuir, and Langmuir-Freundlich (Sips) models using the Origin program to obtain the binding model of $\mathrm{Co}^{2+}$ ions with a Au/chitosan-GO-PAR composite thin film. The fitting shown in Fig. 11 shows that the Sips equation most accurately fit the data plot compared with the Freundlich and Langmuir models.

The comparison of fitted values of the Freundlich, Langmuir, and Sips parameters for $\mathrm{Co}^{2+}$ ion adsorption on a Au/chitosan-GO-PAR composite layer is shown in Table 3. All three 


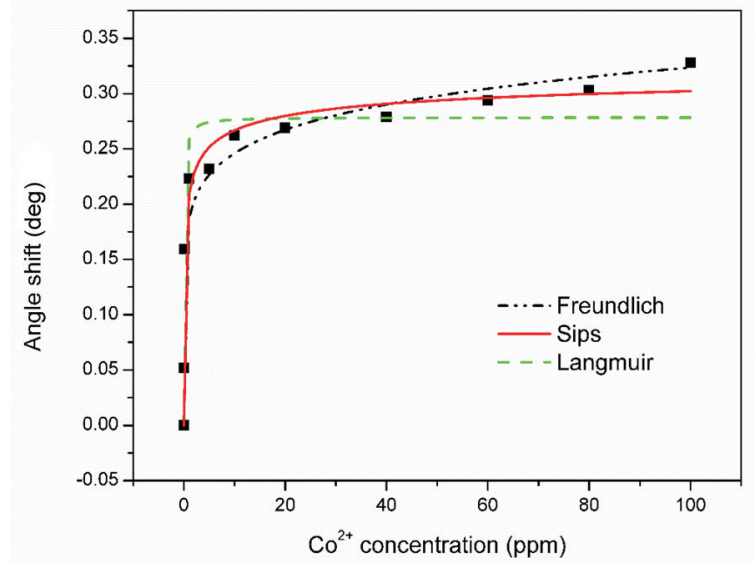

Fig. 11. (Color online) Freundlich, Sips, and Langmuir models of $\mathrm{Co}^{2+}$ in contact with chitosanGO-PAR active layer.
Table 3

Fitted values of Freundlich, Langmuir, and Sips parameters for the adsorption of $\mathrm{Co}^{2+}$ ions on a Au/chitosan-GO-PAR active layer.

\begin{tabular}{lcccc}
\hline Fitting model & $\Delta \theta_{\max }\left(^{\circ}\right)$ & $K\left(\mathrm{ppm}^{-1}\right)$ & $n$ & $R^{2}$ \\
\hline Freundlich & - & 0.187 & 0.119 & 0.94636
\end{tabular}

$\begin{array}{lllll}\text { Langmuir } & 0.27845 & 12.531 & - & 0.93000\end{array}$

Sips

(Langmuir-Freundlich) $\begin{array}{llll}0.33446 & 1.649 & 0.400 & 0.96716\end{array}$

models fitted the data well with high values of the correlation coefficient $R^{2}$, where the Sips fitting has the highest $R^{2}$ value of 0.96716 , followed by the Freundlich fitting (0.94636) and Langmuir fitting (0.93). From the table, the maximum resonance angle shift of the Sips model fitting is closest to the experimental value of $0.33446^{\circ}$, and the maximum resonance angle shift of the Langmuir model fitting of $0.27845^{\circ}$ is much lower than the experimental value. This proves that the Sips model fitted the experimental data best, reducing errors of the parameters. ${ }^{(63)}$ From the Sips model, the affinity constant or binding affinity of $\mathrm{Co}^{2+}$ towards the Au/chitosanGO-PAR active layer was $1.649 \mathrm{ppm}^{-1}$. Overall, the results obtained from the binding model fitting also shows that the Sips model has the highest $R^{2}$ value among the models used and is the most accurate in determining the binding affinity of $\mathrm{Co}^{2+}$ ions with the composite sensor layer.

\section{Conclusions}

In this work, the sensing ability and binding analysis of an enhanced SPR optical sensor towards $\mathrm{Co}^{2+}$ were described. The enhancement of the SPR sensor was proven by comparing the angle shifts of the gold layer only and the PAR-based composite layer. There were no changes in the SPR angle of the gold layer only in contact with $\mathrm{Co}^{2+}$ of different concentrations, whereas the PAR-based composite layer produced a maximum SPR angle shift of $0.328^{\circ}$. The sensitivity of the PAR-based composite layer towards $\mathrm{Co}^{2+}$ was calculated to be $0.2370^{\circ} \mathrm{ppm}^{-1}$ for $\mathrm{Co}^{2+}$ concentrations of 0 to $1 \mathrm{ppm}, 0.0044^{\circ} \mathrm{ppm}^{-1}$ for $\mathrm{Co}^{2+}$ concentrations of 1 to $10 \mathrm{ppm}$, and $0.00069^{\circ} \mathrm{ppm}^{-1}$ for $\mathrm{Co}^{2+}$ concentrations of 10 to $100 \mathrm{ppm}$ from the slope of the data plot. This shows that the PAR-based composite layer had a high sensitivity towards $\mathrm{Co}^{2+}$, especially at lower concentrations. Further analysis showed that the FWHM of the SPR data decreased from 4.29 to $3.50^{\circ}$ as the $\mathrm{Co}^{2+}$ concentration increased from 0 to $100 \mathrm{ppm}$. As a result, the DA of the data increased with the $\mathrm{Co}^{2+}$ concentration. Finally, the SNR was calculated and plotted. The SNR plot was similar to that of the SPR angle shift against the $\mathrm{Co}^{2+}$ concentration. In the 
binding analysis, the data were fitted using Langmuir, Freundlich, and Sips model equations. All models fitted the data well with the Sips model having the highest $R^{2}$ of 0.96716 and giving a binding affinity of $1.649 \mathrm{ppm}^{-1}$.

\section{Acknowledgments}

The authors would like to acknowledge the financial support for this project from the Ministry of Education Malaysia through the Fundamental Research Grant Scheme (FRGS) (FRGS/1/2019/STG02/UPM/02/1) and Putra Grant Universiti Putra Malaysia. The authors would also like to thank the laboratory facilities provided by the Department of Physics and Department of Chemistry, Faculty of Science, Universiti Putra Malaysia. The services provided by the Institute of Advanced Technology and Wireless and Photonic Networks Research Centre, Faculty of Engineering, Universiti Putra Malaysia, are also acknowledged.

\section{References}

1 A. Syahir, K. Usui, K. Y. Tomizaki, K. Kajikawa, and H. Mihara: Microarrays 4 (2015) 228. https://doi. org/10.3390/microarrays4020228

2 C. Ciminelli, C. M. Campanella, F. Dell'Olio, C. E. Campanella, and M. N. Armenise: Prog. Quant. Electron. 37 (2013) 51. https://doi.org/10.1016/j.pquantelec.2013.02.001

3 G. Qiu, S. P. Ng, and C. M. L. Wu: Biosens. Bioelectron. 106 (2018) 129. https://doi.org/10.1016/j.bios.2018.02.006

4 N. Khansili, G. Rattu, and P. M. Krishna: Sens. Actuators, B 265 (2018) 35. https://doi.org/10.1016/ j.snb.2018.03.004

5 P. Englebienne, A. V. Hoonacker, and M. Verhas: Spectroscopy 17 (2003) 255. https://doi. org $/ 10.1155 / 2003 / 372913$

6 E. Stenberg, B. Persson, H. Roos, and C. Urbaniczky: J. Colloid Interface Sci. 143 (1991) 513. https://doi. org/10.1016/0021-9797(91)90284-F

7 P. Pattnaik: Appl. Biochem. Biotechnol. 126 (2015) 79. https://doi.org/10.1385/ABAB:126:2:079

8 N. F. Lokman, A. A. A. Bakar, F. Suja, H. Abdullah, W. B. W. A. Rahman, N. M. Huang, and M. H. Yaacob: Sens. Actuators, B 195 (2014) 459. https://doi.org/10.1016/j.snb.2014.01.074

9 A. A. Zainudin, Y. W. Fen, N. A. Yusof, and N. A. S. Omar: Optik 144 (2017) 308. https://doi.org/10.1016/ j.ijleo.2017.07.001

10 N. A. S. Omar and Y. W. Fen: Sens. Rev. 38 (2018) 106. https://doi.org/10.1108/SR-07-2017-0130

11 M. M. Abdi, L. C. Abdullah, A. R. Sadrolhosseini, W. M. M. Yunus, M. M. Moksin, and P. M. Tahir: PloS One 6 (2011) e24578. https://doi.org/10.1371/journal.pone.0024578

12 W. M. E. M. M. Daniyal, S. Saleviter, and Y. W. Fen: Sens. Mater. 30 (2018) 2023. https://doi.org/10.18494/ SAM.2018.1952

13 Y. W. Fen, W. M. M. Yunus, and N. A. Yusof: Sens. Mater. 23 (2011) 325. https://doi.org/10.18494/ SAM.2011.723

14 S. P. Ng, G. Qiu, N. Ding, X. Lu, and C. M. L. Wu: Biosens. Bioelectrons. 89 (2017) 468. https://doi. org/10.1016/j.bios.2016.04.017

15 P. Singh: Sens. Actuators, B 229 (2016) 110. https://doi.org/10.1016/j.snb.2016.01.118

16 N. Kamaruddin, A. A. Bakar, N. Mobarak, M. S. Zan, and N. Arsad: Sensors 17 (2017) 2277. https://doi. org/10.3390/s17102277

17 Y. W. Fen and W. M. M. Yunus: Sens. Rev. 33 (2013) 305. https://doi.org/10.1108/SR-01-2012-604

18 B. Prabowo, A. Purwidyantri, and K. C. Liu: Biosensors 8 (2018) 80. https://doi.org/10.3390/bios8030080

19 L. He, Q. Pagneux, I. Larroulet, A. Y. Serrano, A. Pesquera, A. Zurutuza, R. Boukherroub, and S. Szunerits: Biosens. Bioelectron. 89 (2017) 606. https://doi.org/10.1016/j.bios.2016.01.076

20 G. Qiu, S. P. Ng, and C. M. L. Wu: Biosens. Bioelectron. 106 (2018) 129. https://doi.org/10.1016/j.bios.2018.02.006

21 W. M. E. M. M. Daniyal, Y. W. Fen, J. Abdullah, A. R. Sadrolhosseini, S. Saleviter, and N. A. S. Omar: Spectrochim. Acta, Part A. 212 (2019) 25. https://doi.org/10.1016/j.saa.2018.12.031

22 Y. W. Fen, W. M. M. Yunus, and Z. A. Talib: Indian J. Phys. 86 (2012) 619. https://doi.org/10.1007/s12648-0120082-6 
23 A. A. Zainudin, Y. W. Fen, N. A. Yusof, S. H. Al-Rekabi, M. A. Mahdi, and N. A. S. Omar: Spectrochim. Acta Part A. 191 (2018) 111. https://doi.org/10.1016/j.saa.2017.10.013

24 Y. W. Fen and W. M. M. Yunus: IEEE Sens. J. 13 (2012) 1413. https://doi.org/10.1109/JSEN.2012.2235311

25 Y. W. Fen, W. M. M. Yunus, and Z. A. Talib: Optik 124 (2013) 126. https://doi.org/10.1016/j.ijleo.2011.11.035

26 S. Saleviter, Y. W. Fen, N. A. S. Omar, W. M. E. M. M. Daniyal, J. Abdullah, and M. H. M. Zaid: J. Nanomater. 2018 (2018) 1. https://doi.org/10.1155/2018/4324072

27 A. Vasilescu, S. Gáspár, M. Gheorghiu, S. David, V. Dinca, S. Peteu, Q. Wang, M. Li, R. Boukherroub, and S. Szunerits: Biosens. Bioelectron. 89 (2017) 525. https://doi.org/10.1016/j.bios.2016.03.040

28 W. M. E. M. M. Daniyal, Y. W. Fen, J. Abdullah, S. Saleviter, and N. A. S. Omar: Optik 173 (2018) 71. https:// doi.org/10.1016/j.ijleo.2018.08.014

29 M. D. A. Roshidi, Y. W. Fen, W. M. E. M. M. Daniyal, N. A. S. Omar, and M. Zulholinda: Optik 185 (2019) 351. https://doi.org/10.1016/j.ijleo.2019.03.118

30 N. S. M. Ramdzan, Y. W. Fen, N. A. S. Omar, N. A. A. Anas, W. M. E. M. M. Daniyal, S. Saleviter, and A. A. Zainudin: Optik 178 (2019) 802. https://doi.org/10.1016/j.ijleo.2018.10.071

31 N. A. S. Omar, Y. W. Fen, J. Abdullah, M. H. M. Zaid, W. M. E. M. M. Daniyal, and M. A. Mahdi: Opt. Laser Tech. 114 (2019) 204. https://doi.org/10.1016/j.optlastec.2019.01.038

32 A. R. Sadrolhosseini, M. Naseri, and H. M. Kamari: Opt. Commun. 383 (2017) 132. https://doi.org/10.1016/ j.optcom.2016.08.065

33 W. M. E. M. M. Daniyal, Y. W. Fen, N. A. A. Anas, N. A. S. Omar, N. S. M. Ramdzan, H. Nakajima, and M. A. Mahdi: RSC Adv. 9 (2019) 41729. https://doi.org/ 10.1039/C9RA07368J

34 S. B. Borah, T. Bora, S. Baruah, and J. Dutta: Groundw. Sustain. Dev. 1 (2015) 1. https://doi.org/10.1016/ j.gsd.2015.12.004

35 K. K. Saxena, B. V. Agarwala, and A. K. Dey: Mikrochim. Acta 57 (1969) 694. https://doi.org/10.1007/ BF01216298

36 J. B. Hunt, S. H. Neece, and A. Ginsburg: Anal. Biochem. 146 (1985) 150. https://doi.org/10.1016/00032697(85)90409-9

37 M. Płotek, R. Starosta, W. Nitek, U. K. Komarnicka, G. Stochel, and A. Kyzioł: Polyhedron 68 (2014) 357. https://doi.org/10.1016/j.poly.2013.11.004

38 A. Hol, U. Divrikli, and L. Elci: Environ. Monit. Assess. 184 (2012) 3469. https://doi.org/10.1007/s10661-0112201-9

39 P. C. Jerónimo, A. N. Araújo, and M. C. B. Montenegro: Sens. Actuators, B 103 (2004) 169. https://doi. org/10.1016/j.snb.2004.04.049

40 T. Liu, G. Li, N. Zhang, and Y. Chen: J. Hazard. Mater. 201 (2012) 155. https://doi.org/10.1016/ j.jhazmat.2011.11.060

41 T. M. Florence and Y. Farrar: Anal. Chem. 35 (1963) 1613. https://doi.org/10.1021/ac60204a020

42 E. L. Silva, P. D. S. Roldan, and M. F. Giné: J. Hazard. Mater. 171 (2009) 1133. https://doi.org/10.1016/ j.jhazmat.2009.06.127

43 A. Karmakar and B. Singh: J. Mol. Liq. 236 (2017) 135. https://doi.org/10.1016/j.molliq.2017.04.005

44 Y. J. Bang, S. Shankar, and J. W. Rhim: Food Packag. Shelf Life 22 (2019) 100399. https://doi.org/10.1016/ j.fpsl.2019.100399

45 F. H. Pollard, P. Hanson, and W. J. Geary: Anal. Chim. Acta 20 (1959) 26. https://doi.org/10.1016/00032670(59)80004-0

46 L. G. Crane, D. Wang, L. M. Sears, B. Heyns, and K. Carron: Anal. Chem. 67 (1995) 360. https://doi. org/10.1021/ac00098a021

47 N. Malcik, O. Oktar, M.E. Ozser, P. Caglar, L. Bushby, A. Vaughan, B. Kuswandi, and R. Narayanaswamy: Sens. Actuators, B 53 (1998) 211. https://doi.org/10.1016/S0925-4005(99)00004-0

48 P. C. Jerónimo, A. N. Araújo, and M. C. B. Montenegro: Sens. Actuators, B 103 (2004) 169. https://doi. org/10.1016/j.snb.2004.04.049

49 N. A. Yusof, and M. Ahmad: Sens. Actuators, B 86 (2002) 127. https://doi.org/10.1016/S0925-4005(02)00157-0

50 M. Z. Elsabee and E. S. Abdou: Mater. Sci. Eng. C 33 (2013) 1819. https://doi.org/10.1016/j.msec.2013.01.010.

51 Z. Zainal, L. K. Hui, M. Z. Hussein, A. H. Abdullah, and I. M. K. R. Hamadneh: J. Hazard. Mater. 164 (2009) 138. https://doi.org/10.1016/j.jhazmat.2008.07.154.

52 G. Eda and M. Chhowalla: Adv. Mater. 22 (2010) 2392. https://doi.org/10.1002/adma.200903689.

53 R. K. Joshi, P. Carbone, F. C. Wang, V. G. Kravets, Y. Su, I. V. Grigorieva, H. A. Wu, A. K. Geim, and R. R. Nair: Science 343 (2014) 752. https://doi.org/10.1126/science.1245711.

54 L. Zi, Y. Huang, Z. Yan, and S. Liao: J. Lumin. 148 (2014) 359. https://doi.org/10.1016/j.jlumin.2013.12.051.

55 A. Shahat, M. R. Awual, and M. Naushad: Chem. Eng. J. 271 (2015) 155. https://doi.org/10.1016/j.cej.2015.02.097.

56 W. M. E. M. M. Daniyal, Y. W. Fen, J. Abdullah, A. R. Sadrolhosseini, S. Saleviter, and N. A. S. Omar: Opt. Express 26 (2018) 34880. https://doi.org/10.1364/OE.26.034880 
57 Y. W. Fen, W. M. M. Yunus, and Z. A. Talib: Optik 124 (2013) 126. https://doi.org/10.1016/j.ijleo.2011.11.035

58 T. T. Wu and J. M. Ting: Surf. Coatings Technol. 231 (2013) 487. https://doi.org/10.1016/j.surfcoat.2012.05.066

59 N. F. Murat, W. M. Mukhtar, A. R. A. Rashid, K. A. Dasuki, and A. A. R. A. Yussuf: 2016 IEEE Int. Conf. Semiconductor Electronics (ICSE) (2016) 244-247. https://doi.org/10.1109/SMELEC.2016.7573637

60 N. H. Kamaruddin, A. A. A. Bakar, M. H. Yaacob, M. A. Mahdi, M. S. D. Zan, and S. Shaari: Appl. Surf. Sci. 361 (2016) 177. https://doi.org/10.1016/j.apsusc.2015.11.099

61 A. K. Sharma, R. Jha, and B. D. Gupta: IEEE Sens. J. 7 (2007) 1118. https://doi.org/10.1109/JSEN.2007.897946

62 Y. S. Ho, J. F. Porter, and G. McKay: Water. Air. Soil Pollut. 141 (2002) 1. https://doi.org/10.1023/A:1021304828010

63 A. R. Sadrolhosseini, A. S. M. Noor, A. Bahrami, H. N. Lim, Z. A. Talib, and M. A. Mahdi: PloS ONE 9 (2014) e93962. https://doi.org/10.1371/journal.pone.0093962

64 S. Yasmeen, M. K. Kabiraz, B. Saha, M. R. Qadir, M. A. Gafur, and S. M. Masum: Int. Res. J. Pure Appl. Chem. 10 (2016) 1. https://doi.org/10.9734/IRJPAC/2016/23315

65 G. P. Jeppu and T. P. A Clement: J. Contam. Hydrol. 129 (2012) 46. https://doi.org/10.1016/j.jconhyd.2011.12.001

66 R. Rahimi, R. Zare-Dorabei, A. Koohi, and S. Zargari: Proc. Int. ECSOC 11 (2014) 1. https://doi.org/10.3390/ ecsoc-18-a017

\section{About the Authors}

Silvan Saleviter graduated from Universiti Putra Malaysia with a B.Sc. in physics in 2017. Then, he continued his studies at the Institute of Advanced Technology, Universiti Putra Malaysia in the field of sensor technology and received his M.Sc. in 2019. His research interest is in the detection of metal ions by surface plasmon resonance spectroscopy.

(silvansaleviter94@gmail.com)

Yap Wing Fen is an associate professor and leads the Applied Optics Laboratory in the Department of Physics, Faculty of Science, Universiti Putra Malaysia. He obtained a first-class degree in physics, majoring in education, and received his Ph.D. in the field of applied opticssurface plasmon resonance in 2012. (yapwingfen@gmail.com)

Nur Alia Sheh Omar received her B.Sc., M.Sc., and Ph.D. degrees in 2014, 2016, and 2020, respectively, from Universiti Putra Malaysia. Her research is on biosensors for the detection of dengue virus using surface plasmon resonance. (nuralia.upm@gmail.com)

Wan Mohd Ebtisyam Mustaqim Mohd Daniyal graduated from Universiti Putra Malaysia with a B.Sc. in physics. Currently, he is studying at the Institute of Advanced Technology, Universiti Putra Malaysia in the field of sensor technology. His current research is on the detection of metal ions using surface plasmon resonance. (wanmdsyam@gmail.com)

Jaafar Abdullah is currently an associate professor in the Department of Chemistry, Universiti Putra Malaysia, Malaysia. He received his B.Sc. and Ph.D. degrees in chemistry from Universiti Kebangsaan Malaysia in 1995 and 2007, respectively. His current research interests are in the use of nanomaterials for the fabrication of biosensors and chemical sensors.

(jafar@upm.edu.my)

Mohd Adzir Mahdi received his B.Eng. degree from Universiti Kebangsaan Malaysia in 1996, and his M.Sc. and Ph.D. degrees from Universiti Malaya in 1999 and 2002, respectively. $\mathrm{He}$ is a professor in the Department of Computer and Communication Systems Engineering, Faculty of Engineering, Universiti Putra Malaysia. His research interests include optical fiber amplifiers and lasers, optical fiber communications, and nonlinear optics. (mam@upm.edu.my) 